Article

\title{
Thermodynamic Rarity and the Loss of Mineral Wealth ${ }^{\dagger}$
}

\section{Antonio Valero * and Alicia Valero}

Research Center for Energy Resources and Consumption (CIRCE), Universidad de Zaragoza, Mariano Esquillor Gómez 15, Zaragoza 50018, Spain; E-Mail: aliciavd@unizar.es

${ }^{\dagger}$ This paper is an extended version of our paper published in ECOS 2014-The 27th International Conference on Efficiency, Cost, Optimization, Simulation and Environmental Impact of Energy Systems.

* Author to whom correspondence should be addressed; E-Mail: valero@unizar.es; Tel.: +34-976-761-863; Fax: +34-976-732-078.

Academic Editor: Ron Zevenhoven

Received: 31 October 2014 / Accepted: 14 January 2015 / Published: 26 January 2015

\begin{abstract}
The second law of thermodynamics and, specifically, exergy analysis have been traditionally used for the assessment and optimization of energy systems. Nevertheless, as shown in this paper, exergy could also constitute a powerful tool for the evaluation of mineral commodities. That said, new or re-defined exergy-based concepts need to be developed. This paper presents Thanatia as a baseline for evaluating the exergy of any mineral in the crust and opens the door to discuss the "thermodynamic rarity" concept as a basis for exergy analyses for mineral systems. Thermodynamic rarity is understood as the amount of exergy needed to obtain a given mineral from a completely degraded state, denoted as Thanatia. The rarer the mineral, the greater the associated exergy costs. It quantifies value, as it relates to concentration, chemical composition and cohesion, key aspects that determine whether a mine is exploitable. The theory further allows one to quantify the gradual loss of mineral capital on Earth as a consequence of "rarefaction processes" that occur at a mineral's end-of-life, when a commodity is wasted, and at its beginning-of-life, where mining ore grades decline after extraction.
\end{abstract}

Keywords: exergy; mineral resources; Thanatia; thermodynamic rarity; exergy cost; mining; beneficiation; exergy replacement cost 


\section{Introduction}

Man's accelerated technological development continues to cause an intensified use of minor and scarce elements, plus a massive use of conventional minerals, such as iron or aluminum ores, construction materials, etc. This, in turn, leads to a net reduction of the planetary mineral endowment. Since the Earth's crust is in no way homogeneous, mining focuses on the extraction of the best ore grades, leaving behind the sub-optimal ones. Declining ore grades imply greater ecosystem destruction and greater amounts of water, materials and energy employed per each additional ton of mineral extracted. The result is that mining is becoming all the more evasive, deeper, remote and resource intensive. If resources are to be preserved for future generations, it is of paramount importance to become aware of this issue.

Unfortunately, the total amount of mineral resources in the Earth is probably unaccountable. That said, the annual loss of the quality (higher grade) minerals that society extracts from the crust can and should be quantitatively considered. Therefore, if the mineral capital on Earth is declining year by year, by how much is it doing so? Assessing this annual loss is not easy. Money, a common unit of measure, cannot be used, because it depends on markets and political decisions that are far removed from the objective reality of a physical loss. Alternatively, the use of mass (tonnage of extracted commodities) turns, for instance, the addition of ounces of gold with million of tons of iron into absurdity. Moreover, as is also the case for tonnage, energy is not sensitive to the quality (ore grade) of the extracted mineral (the energy or the mass of a mineral in a deposit is independent of its ore grade).

What could be used then as the yardstick? If the second law of thermodynamics applies to all physical systems, why not use exergy analysis?

Exergy is a measure of the degree of thermodynamic distinction a system has from the surrounding commonness, and in this sense, it is a measure of an object's rarity. The rarer something is, the greater it stands out. People value distinction and pay higher prices for it. Given that it is only perceived upon comparing something with its surroundings, distinction is deeply related to economic value and with physics. In fact, exergy accurately measures, in energy terms, the distinction of a piece of matter with respect to a given reference environment (R.E.), sometimes also known as the "dead state".

Choosing an appropriate reference environment is key to making exergy analysis suitable for systems other than power plants. In the literature, one can find a good number of discussions regarding the suitability of different proposed reference environments. Certain types of studies search for absolute R.E., like those of Ahrendts [1], Szargut et al. [2], van Gool [3] and Diederichsen [4], to name just a few, whereas others adapt the reference to the problem that they tackle (Bosjankovic [5], Sussman [6] and Gaggioli and Petit [7]). It may be chosen according to the properties of the system one wants to analyze. For instance, when analyzing a simple steam cycle, the reference may be pure water at $15{ }^{\circ} \mathrm{C}$ and 1 bar; in contrast, when analyzing the exergy variation of a river, an appropriate reference state is that of seawater. Even if pure water has exergy with respect to seawater, using seawater for analyzing a steam cycle is unreasonable, and it unnecessarily complicates the calculations. Pure water is a relative R.E., whereas seawater is an absolute one. Contrary to water or energy systems, the concept of the "dead state" becomes more complex when dealing with chemical substances. The Earth's crust is mainly composed of silicates, which all have chemical exergy with respect to the chemical reference species $\mathrm{SiO}_{2}$. Yet, 
in no way is this amount of exergy relevant to a metallurgical reduction process, like, for instance, the conversion of alumina into aluminum.

Following these reflections and bearing in mind that:

- Minerals are a rarity, since they represent between $0.01 \%$ and $0.001 \%$ of the rocks constituting the outer Earth's crust.

- According to the International Energy Agency (IEA), global mining consumes about $8 \%$ to $10 \%$ of global energy resources, mostly fossil fuels.

- The global decrease of mineral ore grades will lead to an escalation of the aforementioned percentages in the near future.

- These resources are, in turn, the raw materials for mining, metallurgical and refining technologies. Moreover, metallurgy is very energy intensive and is far from an automatized processing industry, with a strong influence on global GHG emissions.

- Once the material enters the technological cycle, sooner or later, it becomes oxidized and/or dispersed in the crust, sea, atmosphere or wasted in landfills.

- The scarcity of minor elements is heavily induced by the lack of recycling [8]. Minor metals are profusely used in new technologies, like mobile phones, consumer electronics, computers, and so on. This ever-increasing consumption will sooner or later provoke a disruptive offer with uncontrolled social effects.

- Recycling technologies are an urgent need, and they are far from being cost efficient. There is currently no metal with a recycling rate greater than $50 \%$. This is the case even for precious and rare metals [9].

The authors think that there are strong reasons to consider that the exergy analysis could yield interesting results in the assessment of the Earth's abiotic resources. These are as follows:

1. There has not been any previous attempt to evaluate the rate of the irreversible exergy decrease of the mineral capital. Note that exergy apprehends a loss of quality, too, in contrast to energy or tonnage, which are only sensitive to quantity.

2. Up to now, thermodynamicists have not yet fully explored this field. Thermodynamics has developed techniques for evaluating the exergy of fossil fuels, gases in the air or dissolved substances in water. Yet, the exergy of solids diluted in a large solid matrix renders poor results in identifying exergy as an indicator of value. Moreover, when compared to the exergy of fossil fuels, that of non-fuel minerals is significantly lower, leading to the wrong conclusion that, thermodynamically speaking, non-fuel minerals are less valuable than fossil fuels. Therefore, allocating or valuating a mineral as a function of solely its chemical exergy is debatable, especially in chemical or geological systems. This means that other exergy-related concepts need to be applied.

3. An abiotic resource presents three properties with respect to its solid matrix: composition, concentration or ore grade and cohesion, which are commonly identified as chemical thermodynamic properties. Others, like the environmental impact of mining or the distance to the processing facility, can be related to recovering or shipping operations through exergy 
costs. In fact, mining, metallurgy, manufacturing, recycling, shipping and recovery are process operations that consume exergy. This consumption is named the exergy cost.

4. As is well known, one does not find "pure minerals" in ore deposits, but a combination of aggregates of minerals and rocks containing metals. The cost of extracting, isolating and purifying the various components of a raw material is in no way evident, and the methods used to allocate costs have little or no scientific basis. In this regard, exergy costing is a rigorous and objective way to allocate costs among co-products, by-products and residues, especially in industrial systems with an intensive use of energy, leading to the question: does exergy costing provide a physical and meaningful basis for the economic costing of mineral and metal separation?

In summary, an exergy analysis could, in the authors' opinion, be used to characterize the mineral resource endowment of the Earth. That said, thermodynamics has not been sufficiently established in this field and lacks specific conceptual developments, such as:

- A relative reference environment to evaluate the exergy of a mineral deposit in the crust.

- A way of calculating the exergy "value" of a mineral as a means to provide a straightforward and significant systematic account of the planet's mineral resources.

Such issues are discussed in this paper, which presents Thanatia as a baseline for evaluating the exergy of any mineral in the crust.

\section{Thanatia: The Destiny of Mineral Resources}

In line with the reflections of the Earth Systems Science Partnership, as expressed in the Amsterdam Declaration [10], mankind converts the stored chemical exergy of the Earth into a degraded environment, which is progressively less able to support economic activities as they are currently understood and eventually will fail to sustain life itself. One can imagine a "commercially-dead" planet Earth as a possible end to the "Anthropocene" period (Crutzen and Stoermer [11]). In this scenario, which the authors have called Thanatia from the Greek " $\Theta \alpha \nu \alpha \tau o \varsigma$ " (death), all concentrated materials would have been extracted and dispersed throughout the crust and all fossil fuels would have been burned, leading to an increase in the atmospheric $\mathrm{CO}_{2}$ concentration and mean global temperature, due to the greenhouse effect. Using this as a reference point, every substance that is more concentrated or diluted, warmer or cooler, with a greater or a lower chemical potential, pressure, height or velocity, and so on, will have exergy.

Thanatia constitutes the starting point for assessing the loss of mineral endowment on Earth, but in no way represents the end of life on our planet. It only implies that abiotic resources are no longer available in a concentrated form.

The model behind Thanatia is the "crepuscular Earth" and has been developed with current geochemical and geological information on the atmosphere, hydrosphere and crust in Valero et al. $[12,13]$. The crepuscular atmosphere occurs once all conventional fossil fuel reserves have been depleted and is set to be reached by approximately 2200, with an atmospheric injection of about $2000 \mathrm{GtC}$. Accordingly, the crepuscular atmosphere has a carbon dioxide content of $683 \mathrm{ppm}$, a mean surface temperature of $17{ }^{\circ} \mathrm{C}$ (a peak carbon dioxide induced warming of $3.7^{\circ} \mathrm{C}$ above pre-industrial 
temperatures), a pressure of 1.021 bar and a composition, on a volume basis of $78.8 \% \mathrm{~N}_{2}, 20.92 \% \mathrm{O}_{2}$, $0.93 \%$ Ar and $0.0015 \%$ of trace gases.

Considering that saline water accounts for $97.5 \%$ of the whole hydrosphere, the crepuscular hydrosphere is assumed to have the current chemical composition of the oceans at the average temperature of around $17{ }^{\circ} \mathrm{C}$. This implicitly assumes that all ice sheets have been melted and diluted into saline waters.

The crepuscular continental crust, meanwhile, can approximate the average mineralogical composition of the current Earth's upper crust. This is because as stated in [12], all concentrated mineral resources of fuel and non-fuel origin represent only between $0.01 \%$ and $0.001 \%$ of the Earth's upper continental crust total mass. Accordingly, for Thanatia's upper continental crust, the authors proposed an improved model based on Grigor'ev's [14] mineralogical composition. The resulting crust is composed of nearly 300 minerals, which are the most common ones found on the crust.

At this point, it is important to say that the concept of Thanatia should not be used as a reference environment. Instead, it should be considered as a "baseline environment", as explained next.

The reference environment, the most commonly used of which is arguably that of Szargut [15], is well established within the literature as a tool for chemical exergy calculations. A typical R.E. includes 85 substances with only one chemical substance assigned per chemical element. In contrast, Thanatia should be composed of all (or at least the most abundant) minerals existing currently on Earth. Furthermore, the exact selection of those reference substances depends on the criteria of each individual author. The composition of Thanatia, in contrast, is derived by the geology of the outer Earth spheres [12]. Another important difference between an R.E. and Thanatia is that the concentration factor is absent in a conventional R.E. This only provides the environment's chemical composition. This factor is a very important consideration in the assessment of mineral endowment on Earth, since the greater the difference between the concentration of the mineral in a mine and that in the dispersed crust, the greater the exergy of the deposit, as will be seen in the following section.

The reference environment and Thanatia are separate entities, albeit that the authors recognize that they are closely-related concepts. Nevertheless, conventional reference environments are still needed (in fact, Thanatia has a chemical exergy with respect to a defined absolute R.E.) and constitute a tool for the calculation of chemical exergies.

Henceforth, one must distinguish between the concepts of "exergy" and "exergy resource". Exergy is conventionally calculated from a thermodynamic R.E. In contrast, an exergy resource is calculated from Thanatia as a baseline. Thanatia involves the choosing of a reference bare rock from which a material could be extracted as an alternative to their current mineral deposit. This conceptual complexity can be solved through a minor calculation, since exergy is an additive property. Thus, an exergy resource is obtained as the exergy of the material minus that of the corresponding bare rock constituting Thanatia. Figure 1 shows a graphical representation of the exergy of Thanatia and the current state of the Earth with respect to the reference environment. When minerals are extracted and refined, one is in fact increasing the exergy of the produced raw materials used in the technosphere. This is, however, done at the expense of depleting the mineral deposits from which they stem and the consumption of additional resources (such as fossil fuels) for mining and metallurgical processes. As a consequence, the Earth gradually loses exergy and approximates Thanatia [8]. 


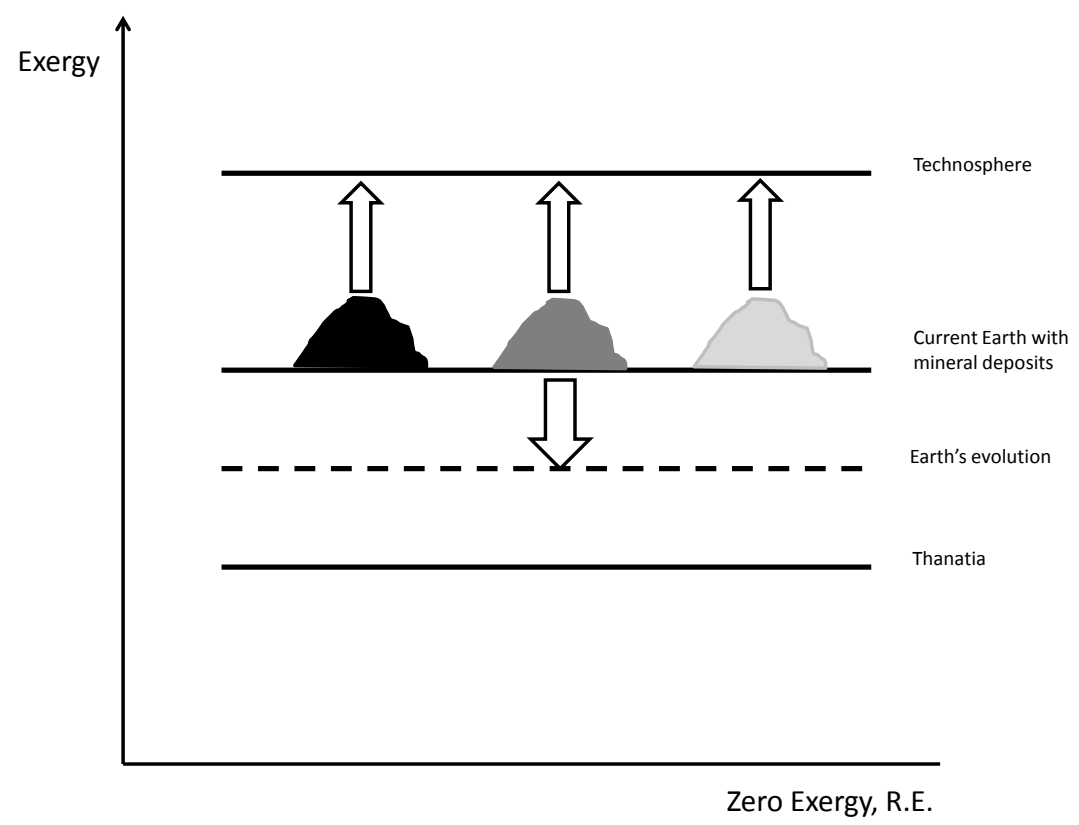

Figure 1. Graphical representation of the exergy associated with the minerals in the technosphere, the mineral deposits and Thanatia with respect to the reference environment.

In summary, exergy reflects the distinction from a given R.E., while measuring resources using the exergy concept means identifying those properties that distinguish a resource from its surroundings, i.e., Thanatia. For a mineral, such properties are the composition, concentration (ore grade) and the cohesion, which are different from the bare rock environment. Considering that all identified concentrated mineral resources of fuel and non-fuel origin represent only between $0.01 \%$ and $0.001 \%$ of the Earth's upper continental crust total mass, one may state first that the exergy concept may well be used as a physical indicator for calculating the world's abiotic resources. Secondly, a world without resources would reasonably constitute the baseline for assessing the global loss of such resources throughout their entire life cycle: mining, through to beneficiating, smelting, refining, stockpiling, manufacturing, fabrication, use, recycling, landfilling and final dispersion.

\section{Exergy, Exergy Costs and Exergy Replacement Costs of Mineral Resources}

Once the Thanatia hypothesis has been postulated, exergy can be used to assess natural resources. In an intuitive way, a mine, a cloud, a glacier, a river or even waste are abiotic resources clearly distinguishable from a completely exhausted planet. These resources are not well-defined thermodynamic systems, but fuzzy. They are not in equilibrium nor homogeneous, and their properties are approximate. That said, their intensive properties can be identified for the exergy calculation of a mine. These are composition, concentration (ore grade) and cohesion, amongst others.

The chemical exergy accounts for the specific composition of a mineral. This component becomes very relevant for the metallurgical processes, as the energy required to refine a given element varies greatly depending on the compound, i.e., refining a sulfide is different from refining an oxide. Chemical exergy is defined as the minimum energy required to chemically obtain a given mineral with the reference 
substances in the chosen reference environment. It can be calculated using the formula provided in [15], through the sum of the mineral's Gibbs free energy and the chemical exergies of its constituent elements.

It should be noted that, whereas chemical exergy is calculated using the conventional R.E. as the baseline, the concentration and comminution exergies are obtained with Thanatia as a baseline. This is because, as explained previously, contrary to Thanatia, the R.E. does not account for the concentration or cohesion state of the reference substances.

Once the mineral is composed from its constituents, the minimum amount of energy that Nature had to spend to bring it from the concentration present in the dispersed state of Thanatia to that found in a mine is effectively the difference obtained in the concentration exergies of a mineral concentration in a mine $\left(x_{m}\right)$ and that of the average concentration in the Earth's crust $\left(x_{c}\right)$. The exergy needed to separate a mineral from its rock matrix increases as its concentration decreases. Such growth is not linear, since according to the second law of thermodynamics, the effort required to extract a mineral from a mine follows an exponential pattern along with ore grade. This pattern is influenced by two factors, one associated with the cohesion state of the mineral with its rock matrix (which makes for the necessity of physical comminution processes, like crushing, grinding and milling) and the second, associated with the need to separate the mineral from its gangue. This can be understood through a simple example: consider two rocks with the same mineral concentration. The grain size of the mineral in Rock A is greater than that of B. Accordingly, and despite the same ore grade, the energy required to separate the mineral particles from the rock is very different. Such a difference is due to the comminution energy required to separate the grains, which increases exponentially with the inverse of the grain size $\left(1 / d_{M}\right)$. Once the particles are released from the rock, the separation energy is equivalent for both cases. It should be stated that in reality, each rock has a statistical distribution of grain sizes. Below a certain grain size, it is no longer cost effective to continue with the milling, and some useful mineral is discarded with the gangue. The former follows a cohesion behavior and can be accounted for through the comminution exergy, where the minimum exergy to comminute a sufficiently large rock is inversely proportional to the final particle size $d_{M}$ [8] (see Equation (1)).

$$
E x_{c o m} \approx 6 F_{r} \rho / \gamma / d_{M}
$$

where $\gamma$ is the surface energy $\left(\mathrm{J} / \mathrm{m}^{2}\right) ; F_{r}$ is the surface factor roughness and $\rho$ its density $\left(\mathrm{g} / \mathrm{cm}^{3}\right)$ of the mineral. Note that, from a reversible point of view, the cohesion exergy is equal to the $E x_{c o m}$ with a minus sign. These values may be obtained from the tables given in [16] for different minerals and rocks.

The second factor follows the entropy law of a mixture, or equivalently, the exergy involved in separating a substance from an ideal mixture of two components (Equation (2)):

$$
\left.E x_{\text {mix }}=R T_{0}\left[\ln \left(x_{i}\right)+\left(\left(1-x_{i}\right) / x_{i}\right)\right) \ln \left(1 x_{i}\right)\right]
$$

This means that the lower the concentration, $x_{i}$, of the mineral in the particle's mixture, the greater the separation work per mass unit of mineral extracted. This factor is commonly many times greater than the first one, especially when the average particle size of the mixture is not micrometric, which is usually the case ([16]).

In summary, as the ore grade, $x_{i}$, and the particle's size tend to zero, the energy needed to extract the mineral from its rock matrix tends towards infinity (see Figure 2). 


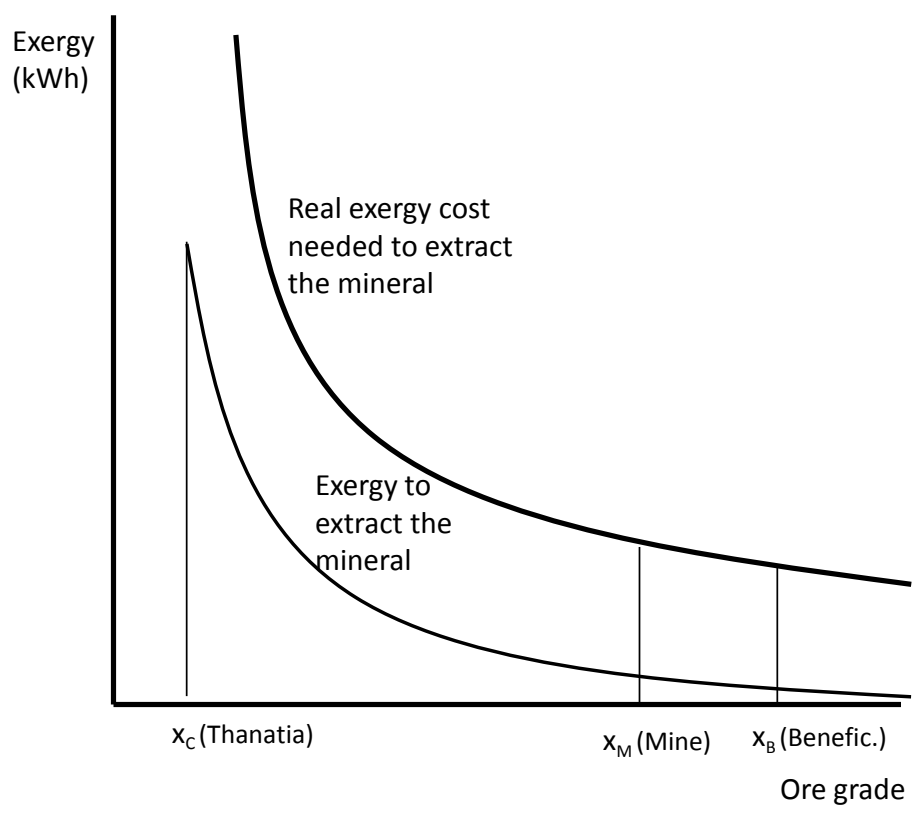

Figure 2. The exergy and exergy cost needed to extract a mineral as a function of the ore grade [8].

Several ideas may be obtained from this analysis: first, it is possible to assess the exergy of a natural abiotic resource, as it is a piece of matter physically distinguishable from a given baseline environment. Second, the exergy of a mineral resource is greater when it presents higher ore grades, favorable composition (sulfides are better than oxides or silicates) and weak cohesion, as it becomes less likely to find it in geological explorations. Third, exergy may be used as a measure of mineral resource rarity. Fourth, as Man is always picking the low hanging fruits, "he" is continuously inducing the depletion of the best mineral ore grades, something that leads him further down the path towards Thanatia. Five, this depletion is not a matter of geological scarcity, given the immensity of the crust, but rather one of the increasing effort required to extract continuously declining ore grades. Six, while ore grades are declining slowly, but progressively, landfilling is an even greater entropic process. In effect, after use, highly-concentrated materials are discarded into worldwide landfills and eventually end up in Thanatia (in the case of fossil fuels, once burnt, they immediately enter Thanatia). These processes can be also described with exergy analysis. That said, even if this analysis is able to explain such phenomena, the exergy values obtained are difficult to interpret. They are too low, if compared with the exergy of fossil fuels, and become insufficient for a true societal appraisal of the resource depletion problem. The researcher needs to resort to an additional concept: the exergy cost. The authors refer to the exergy cost (in $\mathrm{kWh}$ ) of a material as "the actual exergy expenditure in its production process, once the limits of the analysis, the process itself and the efficiencies of each process component have been defined" [17,18]. This also implies a definition as to what can be considered a feedstock, raw material, fuel, product, by-product or waste. This concept is essentially the same as embodied exergy or cumulative exergy cost [15]. It is also more precisely defined than embodied energy, especially when chemical products and/or heat and work are simultaneously produced. In the absence of precise analyses, the embodied energy may be used as a surrogate "number" of the exergy cost. Specifically, mining and refining exergy costs (in $\mathrm{kWh}$ ) can be defined as the actual exergy expenditure needed to extract, concentrate and refine 
a given mineral to produce a given material. Exergy costs are a function of the type of mineral analyzed, its ore grade, extraction and separation technologies and associated energy consumption, which, in turn, vary with time and according to the technological learning curve of extraction. In parallel with exergy, the lower the ore grade, the more energy is required to mine it.

The ratio of the exergy cost and exergy of a given material is named the unit exergy cost, denoted by " $\mathrm{k}$ ". It is linked with ore grade and technological improvement. It is difficult to extrapolate " $\mathrm{k}$ " into the future due to the practical impossibility of predicting changes in scientific and technological knowledge. Another problem with " $\mathrm{k}$ " is that it is a discrete function, as the technology applied can change along with the concentration ranges of a particular deposit. Furthermore, each mining technique (either underground or open-pit) has a particular effect on energy consumption due to a variety of different factors, such as ore grade, grind size, nature, depth and processing route. Such factors have been analyzed for different commodities, including copper, nickel, aluminum and iron through the lifecycle assessment (Norgate and Jahanshahi [19], Norgate and Haque [20] and Norgate and Jahanshahi [21]). Relevant material relating to this is that of Mudd [22-24] and Chapman and Roberts [25].

Bearing in mind the above limitations and the energy data available for mining processes (which is usually very scarce), the authors assume that the same technology is applied for the entire range of concentration between the ore grade $x_{m}$ in the mine and the pre-smelting grade, $x_{r}$, than between the dispersed state found in Thanatia, $x_{c}$ and $x_{m}$.

Given these assumptions, the exergy replacement cost is defined as "the total exergy required to mine and concentrate a mineral deposit from Thanatia, using currently available technologies". Such values are therefore not absolute and universal, as opposed to the exergy property, but assess what it would cost to replace, employing current technology, the mineral wealth that Man extracts, uses and finally disperses.

This is, in short, a "grave to cradle approach", since it is concerned with the amount of actual exergy needed to re-produce a mineral from the depleted state of Thanatia to the conditions of the mine where it was originally found. The exergy difference between Thanatia and the mine increases with the mine's quality (i.e., with its ore grade). This means that as mineral deposits become exhausted, the exergy difference between Thanatia and the mine reduces. At the threshold where all natural resources have been extracted and dispersed, this difference is equal to zero; that is to say, the planet has lost all of its "natural bonus". Since the grave-to-cradle process is hypothetical, the exergy replacement cost is not truly an embodied exergy. Rather, it can be considered a hidden or avoided cost, and hence, both terms cannot be used as synonyms, as is the case for cradle-to-grave analyses [26].

\section{Thermodynamic Rarity}

The idea of replacement cost allows one to move into another concept: "thermodynamic rarity". The Webster Dictionary defines rarity as "something that is valuable because there are few of its kind". Rarity therefore relates to the difficulty in attaining something. In the case of a mineral deposit, it is associated with the improbability of finding and accessing. Once accessed, it also relates to the effort of isolating it from undesired impurities, considering environmental conditions and the availability of water, energy and resources in general for its supply to market. Rarity thus prescribes the character of a natural 
resource to a given mineral deposit. If one considers all of these characteristics from a thermodynamic perspective, they are all rooted in entropy.

Mineral rarity, in turn, requires a definition. When one thinks of rarity generally, there is a tendency to express it in terms of unspecified quantities (i.e., whether there is a little or a lot). However, the authors believe that this concept, when applied to minerals, can be better described in quantified energy terms. Therefore, mineral rarity could arguably be defined as "the amount of exergy resources needed to obtain a mineral commodity from bare rock, using the best available technology".

The authors in their mineral resource assessment have chosen the common bare rock (Thanatia) as the reference baseline. Accordingly, the thermodynamic rarity of minerals is precisely defined as "the actual amount of exergy resources needed to obtain a mineral commodity from Thanatia to the market conditions using the current best available technologies". Consequently, a mineral's "thermodynamic rarity" equates to its natural bonus (measured in terms of exergy replacement costs) plus its mining and beneficiation and prior to the smelting and refining stages. Rarity becomes thus a quantifiable thermodynamic property measured in $\mathrm{kJ}$. Moreover, as it is additive, indirect exergy costs related to water availability, environmental impact and transport from the mine to the customer can be incorporated into the definition.

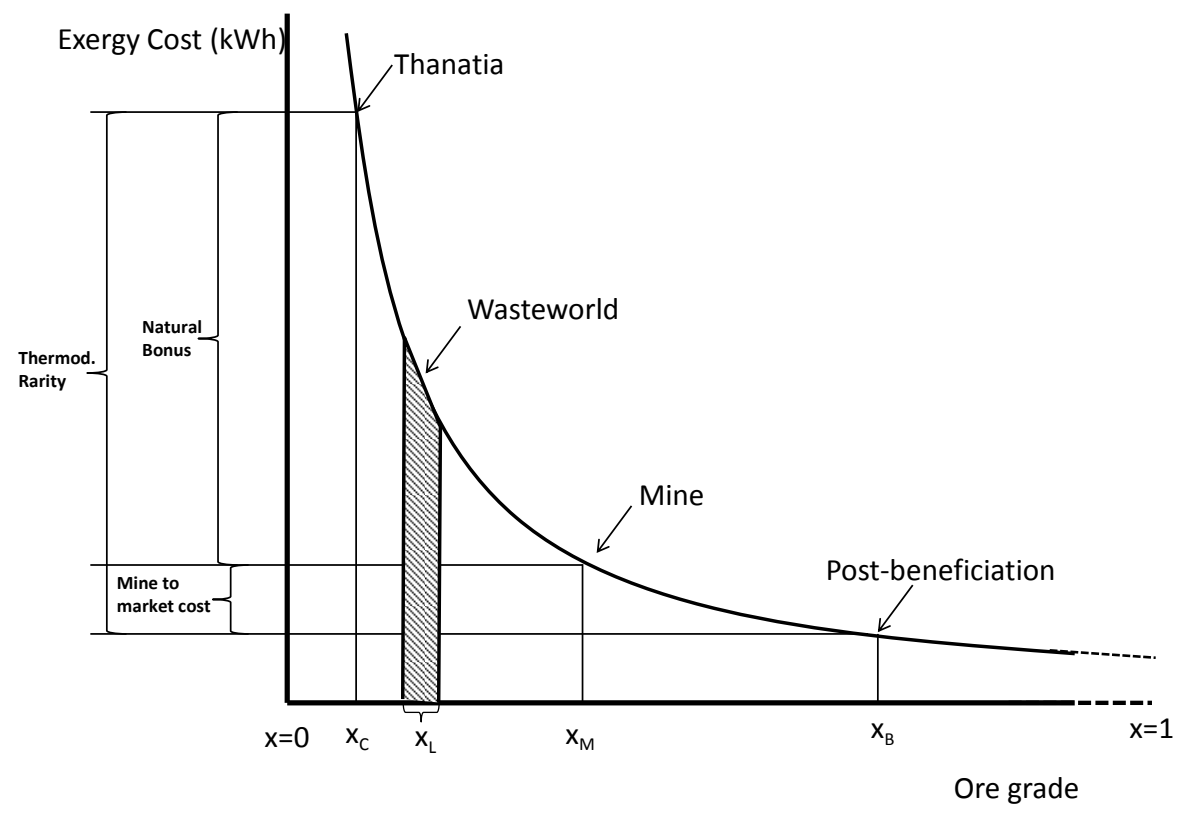

Figure 3. Thermodynamic rarity represents the exergy cost $(\mathrm{kWh})$ needed for producing a given mineral commodity from bare rock to market, i.e., from Thanatia to the mine and then to post beneficiation.

Thermodynamic rarity varies from mineral to mineral, as a function of absolute scarcity in Nature and the state of technological development. Generally speaking, if technology does not change, the thermodynamic rarity of a given mineral will remain constant, since it depends on fixed initial and final states, i.e., on Thanatia and on the commodity's quality following beneficiation, which is usually commercially imposed (see Figure 3). That said, as minerals are extracted, ore grades decline, and hence, 
mining and beneficiation costs increase. Yet, this "natural concentration bonus" with respect to Thanatia simultaneously decreases, and it becomes "easier" to replace low-quality resources or to find new ones (see Figure 4). In other words, at constant technological conditions, the hidden costs are converted into real ones. If, by way of contrast, technological improvements appear, thermodynamic rarity will decrease due to the reduction of both, hidden and real costs (mining and beneficiation) (see Figure 5).

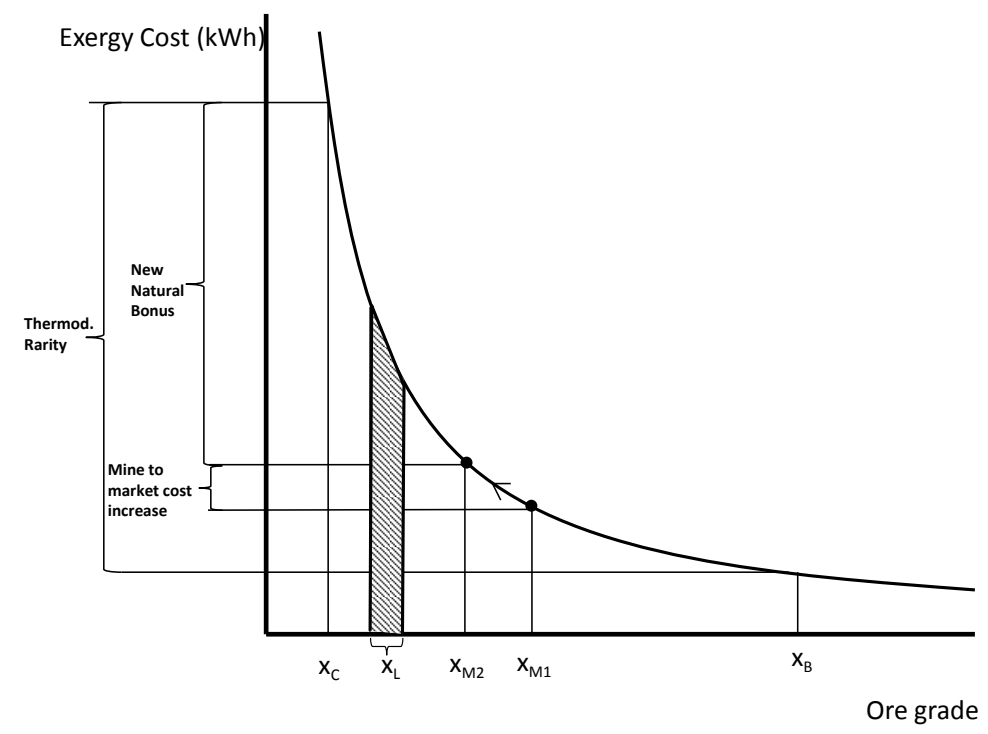

Figure 4. The influence of extraction on thermodynamic rarity, should technology remain constant.

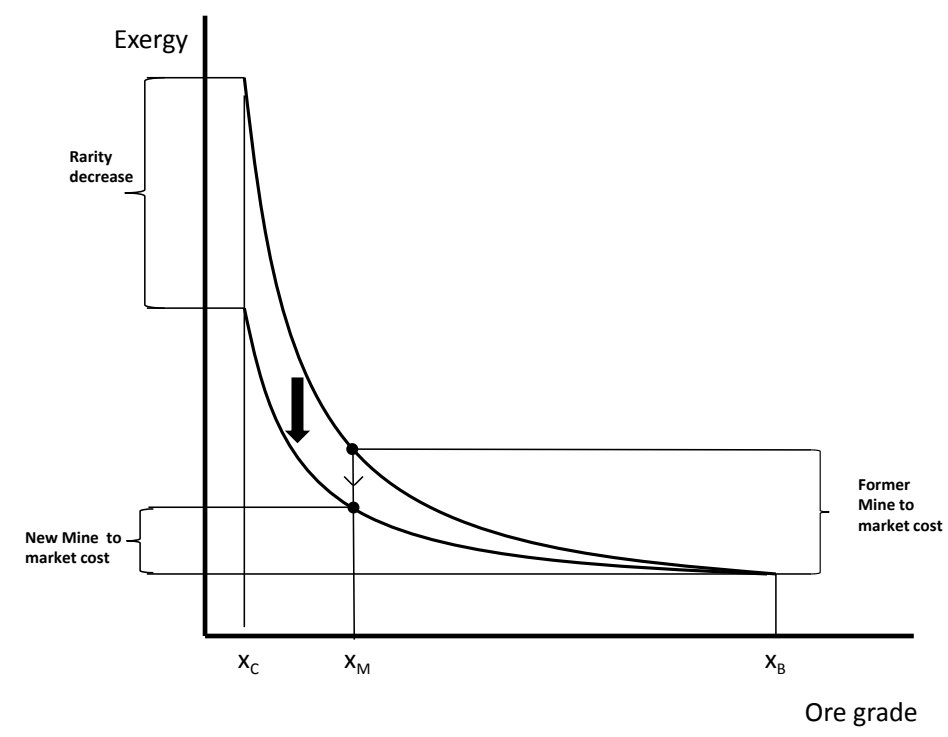

Figure 5. The influence of technological improvements on thermodynamic rarity.

One now may define rarefaction as an induced decline of the concentration of a given commodity, making thus its recovery costly. In the technosphere, rarefaction appears both at the mineral's beginning-of-life (BoL) and at its end-of-life (EoL). At the EoL, it occurs when a metal or mineral 
loses its usefulness and becomes landfilled, incinerated and, sooner or later, dispersed in Thanatia, i.e., it "rarefies". Its irreversible loss is accounted for by its exergy replacement cost from the concentration of the element in the wasted product to the concentration in landfill, $x_{L}$, or if dispersed in Thanatia, $x_{c}$ (see Figures 4 and 5). When this occurs, Man is irreversible converting highly concentrated substances into waste. The name "wasteworld" is used here to express all accumulated worldwide landfills showing a concentration range of around $x_{L}$. At the $\mathrm{BoL}$, when the mineral is mined and beneficiated, what remains in the mine also rarifies, given that the concentration decreases, gradually approaching the limit of Thanatia. This process is is the well known "mining ore grade decline". As a consequence and as stated previously, the amount of exergy needed to extract the next ton of mineral in turn increases. The rarefaction process therefore appears twice, one at the BoL and the other at the EoL. In the authors' opinion, society should be aware of both processes in quantitative terms (kWh).

In summary, rarity is not a mere "yes or no" type question, but rather a cost $(\mathrm{kWh})$ that depends on the given element's scarcity in the crust, the state of technology and the commodity's imposed quality. Furthermore, it is not only a matter of ore grade or geological scarcity, but of exergy costing. It has bearing on global energy consumption and the sustainability of planetary resources, because the greater the thermodynamic rarity, the more difficult it is to obtain a given commodity. In this respect, the economy of mine exploitation is better understood. This is because thermodynamic rarity can unify, into one continuous indicator, all of the following concepts usually found in geological surveys serving to identify resources and reserves data: recoverable, unrecoverable, hypothetical, proved, indicated, inferred, etc. This means that all such concepts are located in a specific interval of ore grade in the thermodynamic rarity function (Figure 6).

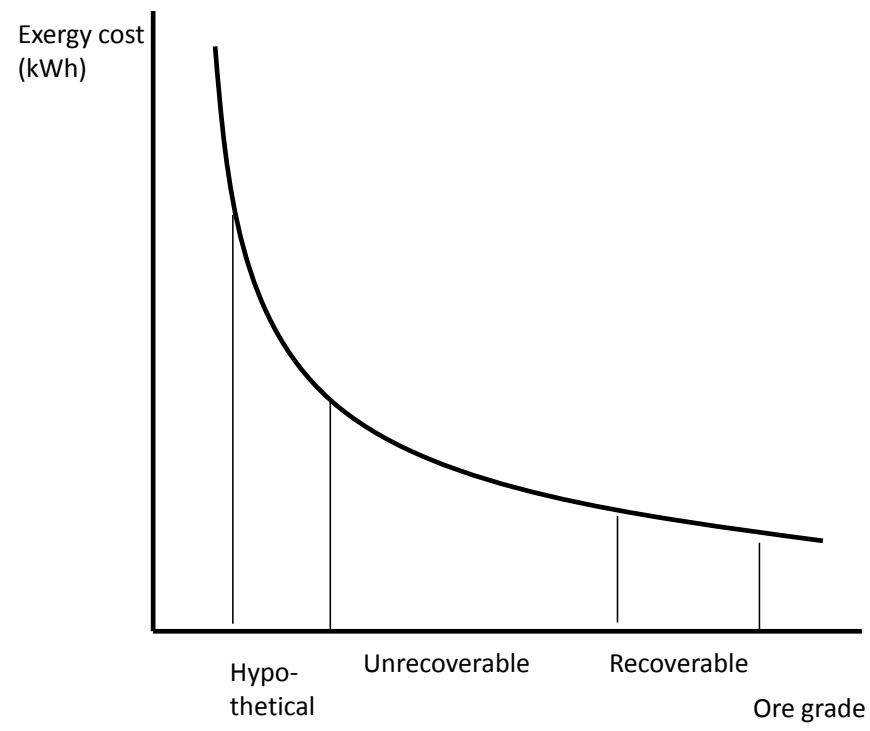

Figure 6. Resources classification as a function of the thermodynamic rarity of a given mineral deposit.

Moreover, thermodynamic rarity, as measured in energy terms, evidently relates to global energy consumption and the impact on the environment. The mineral depletion problem thus becomes not 
an absence of materials, but an insufficient provision of energy. Therefore, as there are no materials without energy and equally no energy without materials, the problem is two-fold or even three-fold if one considers the associated environmental consequences of mineral extraction.

This interpretation solves conceptual dilemmas in the classical mineral discourse, providing answers to questions, such as: are rare earths elements(REE) truly rare? REE are not geologically scarce, but dispersed and chemically challenging to isolate. Therefore, their depletion per se is not a problem, since there are more REE in the crust than, say, copper. The issue comes in their thermodynamic rarity, which is itself derived from several combining factors consisting of concentration, separation and chemical composition. Firstly, exploitable concentrations of REE-containing minerals, such as bastnasite, monazite or clays, are difficult to find, as they are highly dispersed. Secondly, REE occur all together. Some of them, like cerium and lanthanum, are relatively abundant in comparison to the remaining fifteen. Additionally, not all are equally demanded; for instance, dysprosium is a mass used component that prevents demagnetization at high temperatures in $\mathrm{Nd}-\mathrm{Fe}-\mathrm{B}$ permanent magnets. Thirdly, given that the chemical properties of all REE are very similar, their separation, mainly by ion exchange techniques, is complex and inefficient, as in the case of gadolinium. Finally, as with alkaline and alkaline-earth metals, REE need great amounts of energy in the reduction to their metallic state. Therefore, in a number of applications, to save energy, reactants and effort, mischmetal, rare earth oxide (REO) or even the naturally occurring total rare earth oxide (TREO) is commonly used instead of the pure metal. All of the above lead to REE having a very high exergy replacement cost and beneficiation cost, i.e., thermodynamic rarity, when compared to other metals. In short, rare earths are truly rare from a thermodynamic (exergy) perspective.

\section{Conclusions}

The use of the second law of thermodynamics in assessing mineral resources is proven to be useful, although new concepts need to be introduced or refined, including Thanatia, exergy, exergy resource, exergy cost, exergy replacement cost, thermodynamic rarity and rarefaction processes. The first one, Thanatia, is a hypothetical planet Earth, where all fossil fuels and mineral deposits have been depleted and the atmosphere and hydrosphere have changed accordingly. Thanatia forms a necessary basis for the calculating of a mineral's exergy and exergy cost (or its surrogate concept of embodied energy). A special case of exergy cost is the exergy replacement cost, which is the total exergy required to mine and concentrate a mineral deposit from the bare rock, i.e., Thanatia, using currently available technologies. In fact, it is an avoided cost or bonus Nature gives for free. This bonus increases when technology improves and decreases when ore grades decline. From this point on, a new concept is introduced: thermodynamic rarity.

Something is rare or unique if the cost of producing and/or finding it is high. Accordingly, thermodynamic rarity takes into account production costs and geological scarcity. Thereby, thermodynamic rarity is the sum of two costs: a real one, accounting for the actual amount of resources needed to convert a mineral into a commodity, and a hidden one, which represents the free natural bonus for having minerals concentrated and not dispersed throughout the crust. Such hidden and avoided cost is calculated through the so-called exergy replacement cost, which is the amount of $\mathrm{kWh}$ needed to extract 
a given mineral commodity from bare rock with current best available technology. As ore grades decline over continuous extraction, the avoided costs decrease and become real costs. Through this concept, one can easily understand rarefaction processes and put cardinal values ( $\mathrm{kWh}$ ) to rarity and, hence, compare and allocate costs to minerals in a more objective way.

In addition, the theory allows one to understand that the gradual cost increase $(\mathrm{kWh})$ of mining and beneficiation, due to the ore grade decline in each and every exploited mine, is, in fact, one key indicator for accounting for the gradual historical loss of the mineral capital on Earth. Besides, another key indicator would be the annual amount of substances ending in a "wasteworld" or, alternatively, in Thanatia, as is the case of burnt fossil fuels. These two real costs' increase ( $\mathrm{kWh} / \mathrm{kg} \times$ million tons) is directly related to mineral depletion and the annual loss of Earth's concentrated materials endowment.

Finally, these properties could be used to value minerals in a way that protects the geological heritage and the mineral wealth of future generations. Currently, prices only take into account conventional costs associated with mineral extraction and processing. They do not reflect the fact that future generations will need to invest exponentially more mining energy, due to the decrease of the mineral endowment generated in the past. Therefore, it is key that commodity prices take into account this issue so as to offset the higher extraction costs sure to be experienced into the future. In this sense, thermodynamics and, more specifically, exergy replacement costs converted into money units, through energy prices, could be used to objectively value minerals. Additionally, as thermodynamic rarity can be considered almost constant throughout time (provided that technology does not dramatically change), the cumulated replacement costs converted into monetary values should represent the price that former generations would theoretically have to pay those of the future. Obviously, this also means that the current market prices of mineral commodities should increase so as to include replacement costs and to save this money for the future generations. Such thinking is a step towards what constitutes a thermodynamic solution to the very much sought after intergenerational justice.

\section{Author Contributions}

All ideas and concepts have been throrougly discussed and developed between the two authors. The author's order stands for the more experienced Antonio Valero.

\section{Conflicts of Interest}

The authors declare no conflict of interest.

\section{References}

1. Ahrendts, J. Die Exergie chemisch reaktionsfähiger Systeme; VDI-Forschungsheft 579; VDO-Verlag: Düsseldorf, Germany, 1977; pp. 26-33. (In German)

2. Szargut, J.; Morris, D.; Steward, F. Exergy Analysis of Thermal, Chemical, and Metallurgical Processes; Hemisphere Publishing Corporation: New York, NY, USA, 1988.

3. Van Gool, W. Thermodynamics of chemical references for exergy analysis. Energy Convers. Manag. 1998, 39, 1719-1728. 
4. Diederichsen, D. Referenzumgebungen zur Berechnung der chemischen Exergie; VDI-Verlag: Düsseldorf, Germany, 1991; Volume 50, p. 168. (In German)

5. Bosjankovic, F. Reference level of exergy of chemically reacting systems. Forsch. im Ing. 1963, $21,151-152$.

6. Sussman, M. Choosing a reference environment-state for available-energy computations. In Proceedings of the 72nd Annual AIChE Meeting, San Francisco, CA, USA, 25-29 November 1979.

7. Gaggioli, R.; Petit, P. Second Law analysis for pinpointing the true inefficiencies in final conversion systems. A.C.S. Div. Fuel Chem. 1976, 21, 56-65.

8. Valero, A.; Valero, D.A. Thanatia: The Destiny of the Earth's Mineral Resources; World Scientific Publishing: Singapore, 2014.

9. Graedel, T.; Allwood, J.; Birat, J.P.; Reck, B.; Sibley, S.; Sonnemann, G.; Buchert, M.; Hagelüken, C. Recycling Rates of Metals-A Status Report; A Report of the Working Group on the Global Metal Flows to the International Resource Panel; United Nations Environment Programme (UNEP): Paris, France, 2011.

10. 2001 Amsterdam Declaration on Earth System Science. 2001. Available online: http://www.igbp.net/about/history/2001amsterdamdeclarationonearthsystemscience.4.1b8ae20512 db692f2a680001312.html (accessed on 2 January 2015).

11. Crutzen, P.; Stoermer, E. The "Anthropocene". Glob. Chang. Newsl. 2000, 41, 17-18.

12. Valero, D.A.; Valero, A.; Gómez, J.B. The crepuscular planet. A model for the exhausted continental crust. Energy 2011, 36, 694-707.

13. Valero, A.; Agudelo, A.; Valero, D.A. The crepuscular planet. A model for the exhausted atmosphere and hydrosphere. Energy 2011, 36, 3745-3753.

14. Grigor'ev, N.A. The average mineral composition of the upper continental crust. Ural. Geol. J. 2000, 3, 3-21. (In Russian)

15. Szargut, J. Chemical exergies of the elements. Appl. Energy 1989, 32, 269-286.

16. Valero, A.; Valero, D.A. Exergy of comminution and the Thanatia Earth's model. Energy 2012, 44, 1085-1093.

17. Valero, A.; Lozano, M.; Muñoz, M. A general theory of exergy saving. I. On the exergetic cost. In Computer-Aided Engineering and Energy Systems. Second Law Analysis and Modelling; Gaggioli, R., Ed.; The American Society of Mechanical Engineers: New York, NY, USA, 1986; Volume 3, pp. 1-8.

18. Lozano, M.; Valero, A. Theory of the exergetic cost. Energy 1993, 18, 939-960.

19. Norgate, T.; Jahanshahi, S. Assessing the energy and greenhouse gas footprints of nickel laterite processing. Miner. Eng. 2011, 24, 698-707.

20. Norgate, T.; Jahanshahi, S. Low grade ores. Smelt, leach or concentrate? Miner. Eng. 2010, 23, 65-73.

21. Norgate, T.; Haque, N. Energy and greenhouse gas impacts of mining and mineral processing operations. J. Clean. Prod. 2010, 18, 266-274. 
22. Mudd, G.M. The Sustainability of Mining in Australia: Key Production Trends and Their Environmental Implications; Research report 5; Joint Research Report Mineral Policy Institute (MPI) and Department of Civil Engineering, Monash University: Melbourne, Australia, 2007.

23. Mudd, G.M. Gold mining in Australia: Linking historical trends and environmental and resource sustainability. Environ. Sci. Policy 2007, 10, 629-644.

24. Mudd, G.M. The Environmental sustainability of mining in Australia: Key mega-trends and looming constraints. Resour. Policy 2010, 35, 98-115.

25. Chapman, P.; Roberts, F. Metal Resources and Energy; Butterworths: Kent, UK, 1983.

26. Valero, D.A.; Valero, A. From grave to cradle. J. Ind. Ecol. 2013, 17, 43-52.

(C) 2015 by the authors; licensee MDPI, Basel, Switzerland. This article is an open access article distributed under the terms and conditions of the Creative Commons Attribution license (http://creativecommons.org/licenses/by/4.0/). 